\title{
A Peptidoglycan-Remodeling Enzyme Is Critical for Bacteroid Differentiation in Bradyrhizobium spp. During Legume Symbiosis
}

\author{
Djamel Gully, ${ }^{1}$ Daniel Gargani, ${ }^{2}$ Katia Bonaldi, ${ }^{3}$ Cédric Grangeteau, ${ }^{4}$ Clémence Chaintreuil, ${ }^{1}$ \\ Joël Fardoux, ${ }^{1}$ Phuong Nguyen, ${ }^{1}$ Roberta Marchetti, ${ }^{5}$ Nico Nouwen, ${ }^{1}$ Antonio Molinaro, ${ }^{5}$ \\ Peter Mergaert, ${ }^{6}$ and Eric Giraud ${ }^{1}$
}

\begin{abstract}
${ }^{1}$ IRD, Laboratoire des Symbioses Tropicales et Méditerranéennes, UMR IRD/SupAgro/INRA/UM2/CIRAD, Campus International de Baillarguet, TA A-82/J, 34398 Montpellier Cedex 5, France; ${ }^{2}$ CIRAD, UMR BGPI, F-34398 Montpellier, France; ${ }^{3}$ Center for Chronobiology, Division of Biological Sciences, 9500 Gilman Drive, University of California San Diego, La Jolla, CA 92093, U.S.A.; ${ }^{4}$ UMR Procédés Alimentaires et Microbiologiques, Equipe VAIMiS (Vin, Aliment, Microbiologie, Stress), AgroSup Dijon - Université de Bourgogne Franche-Comté, IUVV, Rue Claude Ladrey, BP 27877, 21000 Dijon, France; ${ }^{5}$ Dipartimento di Scienze Chimiche, Complesso Universitario Monte Sant'Angelo, Università di Napoli Federico II, Via Cintia 4, I-80126 Napoli, Italy; and ${ }^{6}$ Institute for Integrative Biology of the Cell, UMR 9198, CNRS/Université Paris-Sud/CEA, Gif-surYvette, France
\end{abstract}

Submitted 15 February 2015. Accepted 2 March 2016.

\begin{abstract}
In response to the presence of compatible rhizobium bacteria, legumes form symbiotic organs called nodules on their roots. These nodules house nitrogen-fixing bacteroids that are a differentiated form of the rhizobium bacteria. In some legumes, the bacteroid differentiation comprises a dramatic cell enlargement, polyploidization, and other morphological changes. Here, we demonstrate that a peptidoglycan-modifying enzyme in Bradyrhizobium strains, a DD-carboxypeptidase that contains a peptidoglycan-binding SPOR domain, is essential for normal bacteroid differentiation in Aeschynomene species. The corresponding mutants formed bacteroids that are malformed and hypertrophied. However, in soybean, a plant that does not induce morphological differentiation of its symbiont, the mutation does not affect the bacteroids. Remarkably, the mutation also leads to necrosis in a large fraction of the Aeschynomene nodules, indicating that a normally formed peptidoglycan layer is essential for avoiding the induction of plant immune responses by the invading bacteria. In addition to exopolysaccharides, capsular polysaccharides, and lipopolysaccharides, whose role during symbiosis is well defined, our work demonstrates an essential role in symbiosis for yet another rhizobial envelope component, the peptidoglycan layer.
\end{abstract}

The rhizobium-legume interaction leads to the formation of new plant organs, the nodules, in which the bacteria fix nitrogen to the benefit of the host plant and receive in exchange a carbon source. The establishment of this symbiotic organ relies on the plant perception of bacterial signals, the Nod factors (NF) that control the infection process and the nodule organogenesis (Oldroyd 2013). In some rare cases, NF are

D. Gully and D. Gargani contributed equally.

Corresponding author: E. Giraud; E-mail: eric.giraud@ird.fr

*The $\boldsymbol{e}$-Xtra logo stands for "electronic extra" and indicates that three supplementary figures and three supplementary tables are published online.

(c) 2016 The American Phytopathological Society dispensable, as has been described for some tropical legumes of the Aeschynomene genus infected by photosynthetic Bradyrhizobium strains (Giraud et al. 2007) or as has been reported more recently for a soybean cultivar (Glycine max cv. Enrei) that could be nodulated by a mutant of $B$. elkanii USDA61 unable to produce NF (Okazaki et al. 2013). In these interactions, one or more bacterial signals permitting nodule organogenesis and infection remain to be disclosed.

Following these early phases, the rhizobia are chronically maintained within nodule cells, where they differentiate into an endosymbiotic form, the bacteroids, able to fix atmospheric nitrogen. Bacteroid formation can be accompanied by drastic morphological modifications of the bacterial cell. Depending on the host plant, the bacteroid cells can be strongly enlarged into an elongated shape known as E-morphotype bacteroids or into a sphere known as S-morphotype bacteroids. E- and S-morphotype bacteroids are polyploid and their membranes have become porous. In addition, they have lost their reproductive capacity and are, therefore, terminally differentiated (Kondorosi et al. 2013). In other legumes, these morphological changes do not take place and bacteroids are, compared with the free-living state, unmodified or of the $U$ morphotype and do not lose their reproductive capacities (Kondorosi et al. 2013).

In the legume Medicago truncatula, which forms E-morphotype bacteroids, it has been clearly established that a class of peptides, named nodule-specific cysteine-rich peptides (NCR), govern the terminal bacteroid differentiation (Van de Velde et al. 2010). More recently, NCR-like peptides have also been identified in some Aeschynomene species in which they appear to be important for the differentiation of E- and S-morphotype bacteroids (Czernic et al. 2015). However, the bacterial targets of the NCR peptides remain largely unknown and it is unclear how these host-produced peptides provoke the metamorphosis of the rhizobia from small, rodshaped bacteria into the large, elongated or spherical bacteroids.

The peptidoglycan (PGN) is a major determinant of the bacterial cell shape (Typas et al. 2012; Young 2003). Remarkably, the cell shape of many Escherichia coli mutants affected in the PGN structure resembles E- or S-morphotype bacteroids (Nelson and Young 2001; Santos et al. 2002; Young 2003). Therefore, we propose that the morphogenesis of rhizobia 
into E- or S-morphotype bacteroid is associated with changes in the PGN cell-wall architecture.

The DD-carboxypeptidase (DD-CPase) enzymes, which belong to the low-molecular weight penicillin-binding proteins (PBP) family, are among the most prominent PGN-modifying enzymes that play a role in the maintenance of cell shape (Ghosh et al. 2008; Nelson and Young 2001; Young 2003). In contrast to the high-molecular weight PBP that synthesize the PGN, the DD-CPases are thought to regulate the degree of cross-linking between glycan chains. Indeed, by removing the terminal D-alanine from the ends of peptide side-chains, they prevent the transpeptidation reaction. Bacteria often possess several DD-CPases and this multiplicity could be important to fine-tune their morphology in response to environmental conditions. On the other hand, functional redundancy between them could explain why these enzymes are nonessential for growth under laboratory conditions and why their specific physiological roles still remain elusive (Ghosh et al. 2008).

In this paper, we have identified three DD-CPases in the photosynthetic Bradyrhizobium sp. strain ORS278, a symbiont of Aeschynomene indica, and examined their physiological role. We found that one of them, DD-CPase 1, is critical for symbiosis and, in particular, during the bacteroid morphogenesis step. DDCPase 1 is characterized by the presence of a C-terminal PGNbinding SPOR domain that is absent in the other two DD-CPases. To investigate if SPOR domain DD-CPases play a general role in rhizobium-legume symbiosis, we constructed mutants in other Bradyrhizobium strains (ORS285 and Bradyrhizobium diazoefficiens USDA110, formerly named Bradyrhizobium japonicum) that have different host specificities and exhibit distinct bacteroid morphotypes according to their host plants.

\section{RESULTS}

\section{Photosynthetic Bradyrhizobium sp. strain ORS278 has three genes encoding putative DD-CPases.}

BLAST searches on the ORS278 genome using DD-CPase sequences of known function (DacA, DacC, and DacD from E. coli) as query permitted the identification of three coding sequences (BRADO4549, BRADO3826, BRADO6583) that are scattered over the genome and encode putative DD-CPases (Supplementary Fig. S1). The corresponding proteins, annotated DD-CPase1 to DD-CPase3, respectively, exhibit a low level of identity (22.6 to 26\%) between each other. All contain a peptidase S11 domain (PFAM00798) that is characteristic for the DD-CPase family. In addition, the C-terminus of DD-CPase 1 contains a peptidoglycan-binding domain known as a SPOR domain (PFAM05036), while DD-CPase2 contains a PFAM07943 domain of unknown function initially identified in DacA of E. coli. For each of these three DD-CPases, a homolog with high sequence identity $(>65 \%)$ could be identified in all the photosynthetic and nonphotosynthetic Bradyrhizobium strains whose genome has been sequenced.

\section{Phenotypic properties of the three DD-CPase mutants in the ORS278 strain grown under free-living conditions.}

To determine the role of these different DD-CPases on bacterial cell physiology, a mutant of each individual $D D$ CPase gene was constructed by insertion of the nonreplicative plasmid pVO155-npt2-GFP into the coding region. Plasmid pVO155-npt2-GFP, harbors the promoter-less gusA reporter gene and the green fluorescent protein ( $g f p)$ gene under control of the constitutive promoter nptII (Okazaki et al. 2016). Cultivated in yeast-mannitol (YM) medium, the three $D D$-CPase mutants displayed a similar growth rate as the wild-type (WT) strain, with a generation time between 9 to $10 \mathrm{~h}$ (data not shown). Light microscopic analysis of the DD-CPase mutant cells grown in liquid medium did not reveal any morphological disorders (Fig. 1A). Like the WT strain, the mutant bacteria cells were rodshaped and measured about $1 \mu \mathrm{m}$ long. On plates, the DD-CPase mutants form smooth colonies with regular borders, indistinguishable from the WT strain (data not shown), indicating that the DD-CPase mutations do not induce gross modifications in the production of surface polysaccharides such as exopolysaccharides (EPS) or lipopolysaccharides (LPS). Indeed, LPS mutants produce rough colonies with irregular borders (Busset et al. 2016).

The PGN plays a key role in protecting the cell from changes in osmotic pressure. Therefore, we analyzed the growth of the mutants in the presence of increasing amounts of $\mathrm{NaCl}$. As compared with the WT strain, only the DD-CPasel mutant exhibited a higher sensitivity to saline stress (Fig. 1B). Since the alteration of the PGN structure could also lead to disorders of the outer membrane (Gallant et al. 2005; Ghosh et al. 2008), we have examined the ability of the mutants to cope with detergent (sodium dodecyl sulfate [SDS]) stress, using a disk diffusion assay. All mutants had the same SDS-sensitivity as the WT strain (Fig. 1C), indicating that the different DD-CPase mutations have no impact on the stability of the outer membrane.

We also took advantage of the presence of the $g u s A$ reporter gene, introduced in the mutated genes by the plasmid insertion, to follow the expression of the three DD-CPase genes at different time points of the growth curve. During all growth phases, an expression could be observed for DD-CPase 1 and DD-CPase3, whereas the expression of $D D-C P a s e 2$ was close to the limit of the detection level (Fig. 1D). Taken together, the above data indicate that none of the three individual $D D$-CPase genes plays a critical role for the growth in free-living conditions.

\section{DD-CPase1 affects the level of PGN reticulation.}

To investigate if and how the DD-CPases affect the PGN composition in the Bradyrhizobium sp. strain ORS278, we have analyzed, by reverse-phase high-pressure liquid chromatography (HPLC) and mass spectrometry, the muropeptide fractions obtained after digestion of purified PGN. Since only the $D D$ CPasel mutant had an impact on the symbiosis (discussed below), we have focused on this particular mutant. As shown in Supplementary Table S1, the PGN composition of the mutant exhibited some relevant differences with respect to the muropeptide profile of the WT. Our results pointed to the presence of a significant level of dimeric muropeptide species in the DD-CPasel mutant, which were nearly absent in the WT, indicating a greater degree of PGN cross-linking in the mutant. This observation was expected, since the biochemical activity of DD-CPases is the removal of the terminal D-alanine in $N$-acetylmuramyl pentapeptide residues and the terminal alanine is necessary for the reaction of cross-linking by the transpeptidases (Ghosh et al. 2008). This confirmed the critical role of the DD-CPasel in Bradyrhizobium sp. strain ORS278 in the regulation of the degree of PGN cross-linking.

\section{Only the DD-CPase1 mutant is altered in symbiosis.}

We next investigated the ability of the three $D D$-CPase mutants to establish a symbiotic relationship with $A$. indica plants. Observations were made at 14 days postinoculation (dpi), when WT nodules are mature and functional (Bonaldi et al. 2011). As shown in Figure 2, no significant difference was observed between the growth of the plants inoculated with the WT strain and the DD-CPase 2 or DD-CPase 3 mutants (Fig. 2A), the number of nodules per plant (Fig. 2E) and the nitrogenase activity measured by the acetylene reduction assay being comparable (Fig. 2D). Cytological analysis performed by confocal microscopy showed that the mutated bacteroids displayed a spherical shape similar to that observed for WT bacteroids (Supplementary Fig. S2). As a WT reference, we used a strain carrying the pVO155-npt2-GFP 
plasmid inserted in the BRADO5083 gene. This gene encodes a protein of unknown function and previous studies did not reveal any particular symbiotic defect due to the plasmid insertion.

In contrast, we observed a strong effect of the DD-CPase1 mutation on symbiosis. A. indica plants inoculated with the $D D$-CPase 1 mutant had a nitrogenase activity that represented only $25 \%$ of the activity measured for plants inoculated with the WT strain (Fig. 2D). This weak nitrogenase activity led to typical nitrogen-starvation symptoms such as foliar chlorosis and reduced plant growth (Fig. 2A). The nitrogen-fixation defect did not result from a reduction of nodule numbers, since plants inoculated with the mutant actually contained about twice as many nodules compared with plants inoculated with the WT strain (Fig. 2E). However, two classes of nodules could be distinguished: i) tiny yellow-colored nodules whose development was aborted (the majority of nodules) and ii) a small proportion of WT-like, green nodules (Fig. 2B, C, and E).

We can exclude the possibility that the absence of phenotypes in the DD-CPase 2 or DD-CPase 3 mutants or the variable phenotype in the $D D$-CPase 1 mutant is the result of reversion of the mutations by excision of the pVO155-npt2-GFP plasmid, because the entire population of bacteria in all the nodules elicited by these mutants was tagged by GFP (Fig. $2 \mathrm{~K}$ to R), indicating maintenance of the plasmid. Moreover, we also constructed a deletion mutant of DD-CPase 1 by double crossingover. As shown in Supplementary Figure S3, we observed that this deletion mutant behaved similarly to the insertion mutant and also induced the formation of a mixture of tiny and WT-like nodules.

Cytological observations revealed that, in the tiny nodules, the bacterial infection was generally blocked at the level of the epidermis (Fig. 2H). In some cases, the bacteria had infected the central tissue intracellularly, but only a few bacteria were present per plant cell and they appeared not differentiated or only slightly elongated (Fig. 2P). Brownish compounds that autofluoresced in the red spectrum (excitation, $488 \mathrm{~nm}$; emission, 600 to $660 \mathrm{~nm}$ ) were observed in these nodules (Fig. 2I and L). This is indicative of the accumulation of polyphenol compounds that are generally associated with plant defense responses, as described before in other legumes, such as Medicago spp. (Bourcy et al. 2013; Vasse et al. 1993).

Observation of the WT-like nodules elicited by the $D D$ CPasel mutant revealed also the presence of plant defense reactions (Fig. 2J and $\mathrm{M}$ ). The central tissue was rather uniformly infected but, in contrast to the WT bacteroids, which were all spherical (Fig. 2O), morphologically aberrant bacteroids could be observed for the mutant. Indeed, in the same host cells, a mixture of elongated and extremely enlarged spherical bacteroids could be seen (Fig. $2 \mathrm{~N}$ and Q). In addition, in some cases, the cytoplasm of the plant cell was stained by GFP, suggesting that the bacteria had burst, releasing their content into the host cell (Fig. 2R).

Transmission electron microscopy (TEM) images showed the striking spherical and uniform shape of WT bacteroids (Fig. $3 \mathrm{~A}$ and D). Notably, we also observed, in some instances, symbiosomes containing dividing bacteroids (Fig. 3H). Thus, despite their polyploid state (Czernic et al. 2015), the bacteroids still maintain a capacity to divide. TEM observations of the WT-like nodules from the DD-CPase1 mutant showed different stages of degeneration of both bacterial and plant cells. Some plant cells had collapsed, their morphological integrity lost and their electron-dense cytoplasm only displaying ghost bacteria (Fig. 3I and J). In contrast, other cells kept their morphological integrity and they contained several typical organelles such as the nucleus and mitochondria, indicating that
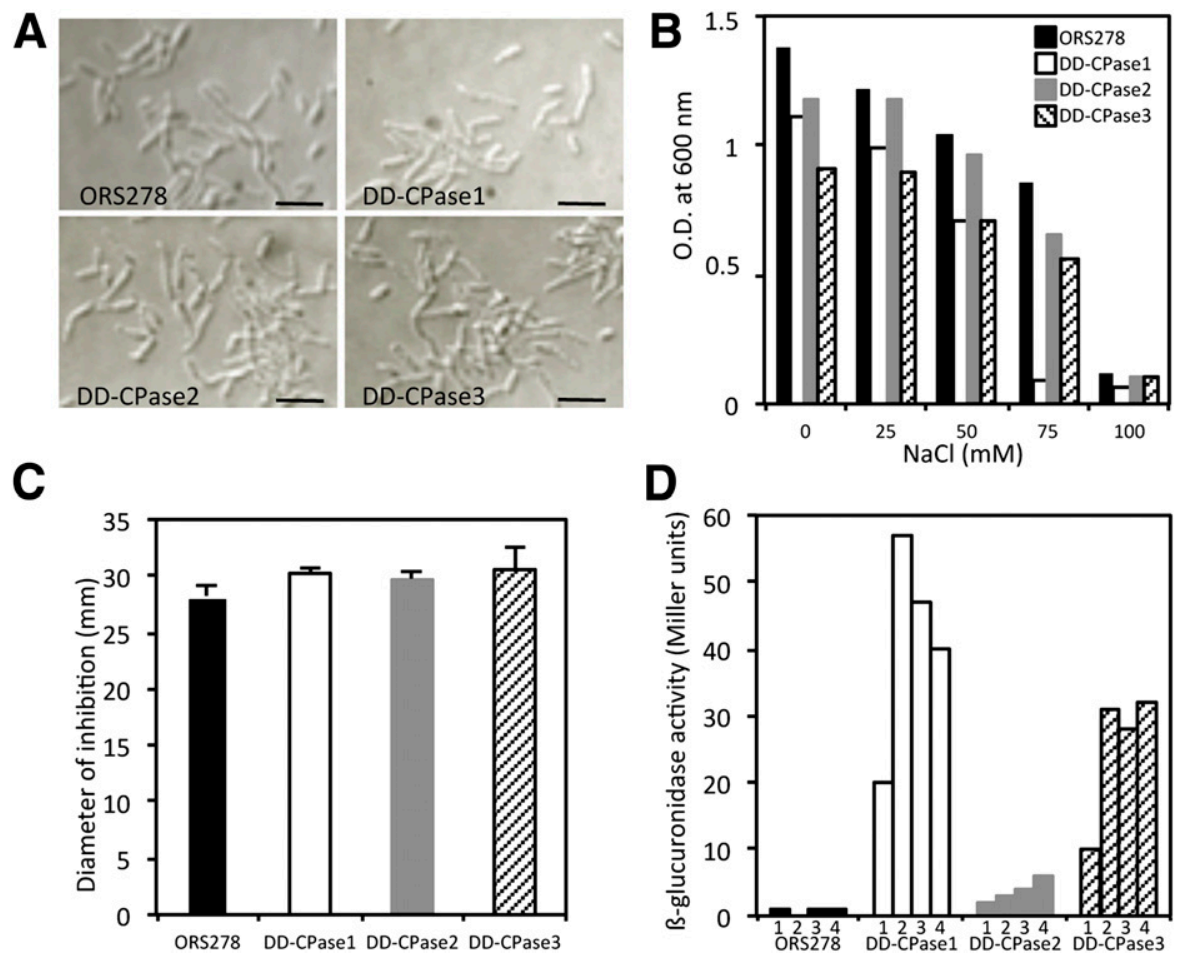

Fig. 1. Phenotypic properties of the ORS278 $\triangle D D$-CPase mutants cultivated in free-living conditions. A, Cells from ORS278 and the three DD-carboxypeptidase (DD-CPase) mutants cultivated in yeast-mannitol medium and observed in exponential growth phase $(60 \mathrm{~h})$ by phase-contrast microscopy. Bars $=1 \mu \mathrm{m} . \mathbf{B}, \mathrm{NaCl}$ and $\mathbf{C}$, sodium dodecyl sulfate resistance of ORS278 and the ORS278 $\triangle D D$-CPase mutants measured after incubation for 5 days at $37^{\circ} \mathrm{C}$. Data in B are the means of duplicate experiments. Error bars in C represent standard deviation $(n=9)$. D, Expression analysis of the ORS278 DDCPases. The $\beta$-glucuronidase activity (in Miller units) was estimated at different time points ( 1 to 4 days) of the growth of the three $D D$-CPase mutants containing the gusA reporter gene. 
they were still active (Fig. 3B and C). In these last cells, bacteroids exhibited a very high heterogeneity in shape and size. Some $D D$-CPase 1 bacteroids displayed aberrant morphological distortions, like the presence of buds or outgrowths (Fig. 3B, $\mathrm{C}$, and E). However, the contour of the DD-CPase1 bacteroids was generally well defined with distinguishable inner and outer membranes (Fig. 3G). Mutant bacteroids were surrounded by a symbiosome membrane and single or multiple bacteroids could be found in one symbiosome (Fig. 3B and F). Despite these morphological abnormalities, it appeared that some DD-CPase 1 bacteroids can maintain a metabolic activity, as the accumulation of polyhydroxybutyrate granules (electron-transparent areas) could be detected as well as the presence of dark granules that likely correspond to polyphosphate granules and dense fibrillar nuclear material (Fig. 3B, F and G). This metabolic activity could account for the weak nitrogenase activity detected in the plants inoculated with the mutant. Taken together, these data show that mutation of the DD-CPasel gene affect different steps of the symbiotic process. On one hand, the mutant is affected in the early steps of the infection process and induces plant defense responses, and on the other hand, bacteroid differentiation is drastically impaired. Considering the gene context, it is very unlikely that the symbiotic
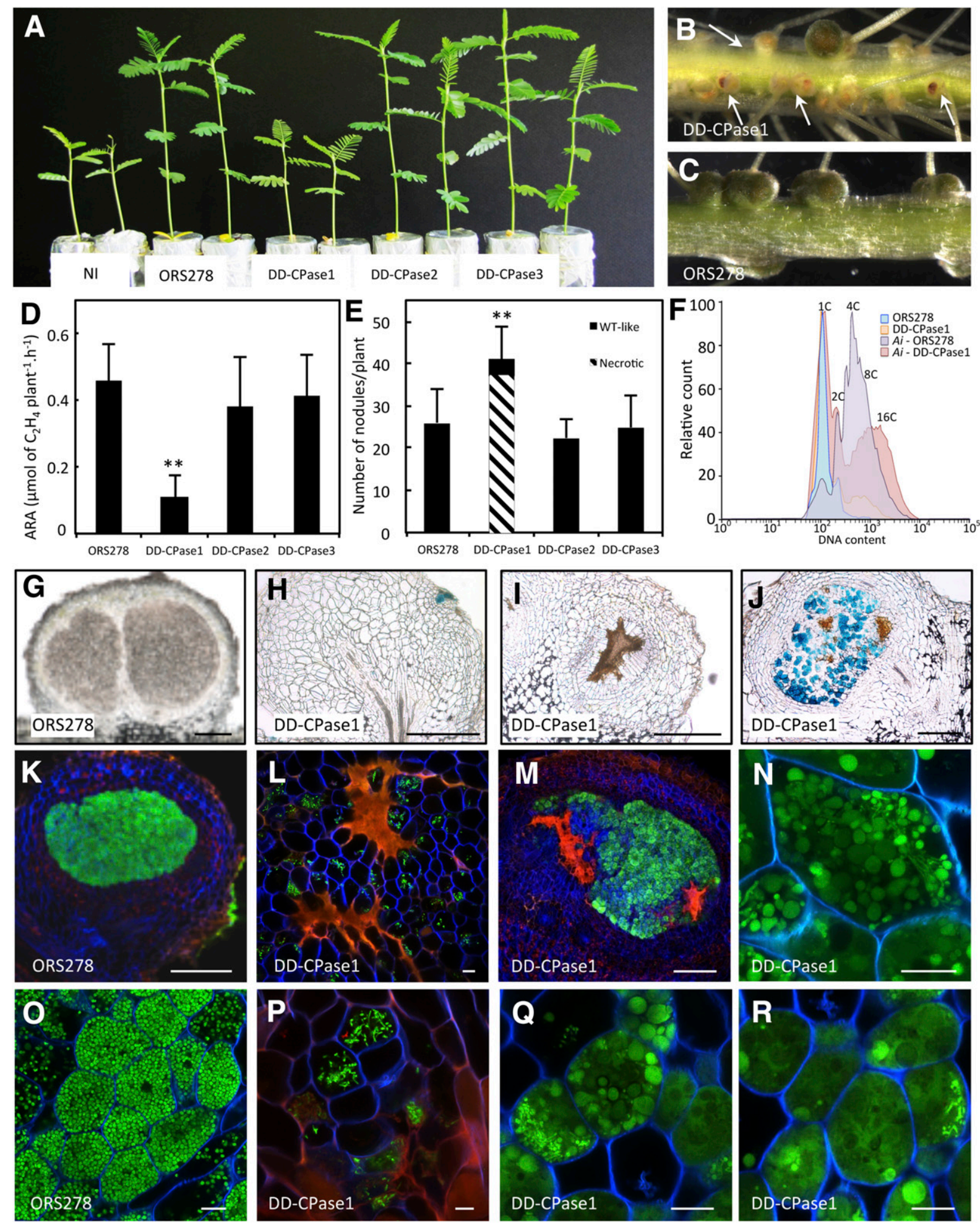
deficiencies observed for the DD-CPasel mutant were due to a polar effect, and we have to conclude that they are the consequence of the missing DD-CPase1 activity in the mutant.

\section{Both DD-CPase1 and DD-CPase3}

\section{are expressed during symbiosis.}

To analyze the expression level of the different $D D$-CPases in planta, we made use of the gusA reporter gene present in the mutants. A strong X-Gluc staining was observed with $D D$-CPase 1 and $D D$-CPase 3 mutants, indicating that both genes are highly expressed in planta. In comparison with the two others, the $\mathrm{X}$-Gluc staining with the DD-CPase 2 mutant was extremely weak, indicating that the gene expression in planta is low, similar to what we found under free-living conditions. The high level of $D D$-CPase 3 expression suggests that this enzyme is important during symbiosis, despite the absence of a detectable phenotype of the corresponding mutant. This apparent inconsistent data could be explained by a functional redundancy between the two $D D$-CPases, i.e., $D D$-CPase 1 could complement $D D$-CPase 3 in the corresponding mutant. The opposite cannot be the case, considering the drastic symbiotic phenotype observed for the $D D$-CPasel mutant. We have tried to construct a DD-CPase 1 and DD-CPase 3 double mutant. However despite several attempts using different strategies, we failed to isolate such a double mutant. This suggests that the presence of at least one of these two DD-CPases is essential for bacterial survival.

\section{DD-CPase1 bacteroids display a higher ploidy level.}

The DD-CPase 1 protein differs from the other two DD-CPases by the presence of a C-terminal SPOR domain. All four E. coli proteins containing a SPOR domain (FtsN, DamX, DedD, and RlpA) localize to the septal ring and are part of the cell-division machinery (Arends et al. 2010). This suggests that DD-CPase1 could be a cell-division protein. The drastic enlargement of the cell size in some of the mutant bacteroids could indicate that those cells are dividing less than usual and is in agreement with a function of DD-CPase 1 during division. To support this hypothesis, we compared the ploidy level of WT and the $D D$ CPase 1 mutant in free-living and symbiotic states by cytometry. As shown in Figure 2F, no difference in the DNA content was observed between the WT and the mutant cells cultivated in vitro. In contrast, in $A$. indica nodules, the DNA content of the DD-CPasel bacteroids reached a higher level than of the WT bacteroids, i.e., around 16 genome complements (16C) for the DD-CPase 1 bacteroids against $4 \mathrm{C}$ to $8 \mathrm{C}$ for the WT bacteroids.

\section{Symbiotic role of DD-CPase1 in other Bradyrhizobium strains.}

To investigate whether DD-CPase1 also plays a symbiotic role in Bradyrhizobium strains that exhibit distinct bacteroid morphotypes (E or $U$ morphotype), we mutated the orthologous gene in the ORS285 and B. diazoefficiens USDA110 strains. In contrast to ORS278, ORS285 does contain the canonical nodABC genes and is able to use a NF-dependent or a NF-independent symbiotic process (Bonaldi et al. 2011). As for the ORS278 strain, ORS285 bacteroids are spherical in A. indica, whereas in A. afraspera, which uses a NF-dependent process, they are elongated (Bonaldi et al. 2011). Bacteroids of the B. diazoefficiens USDA110 strain display a $U$ morphotype in soybean nodules, whereas they are of the E morphotype in A. afraspera (Ledermann et al. 2015).

The ORS285 $\triangle D D$-CPasel mutant tested on A. indica displayed a similar phenotype as observed for the corresponding mutant in the ORS278 strain, i.e., a plant-growth defect resulting from a weak nitrogen-fixation efficiency, a large majority of necrotic nodules and bacteroids that have heterogeneous shapes (Fig. 4A, B, D, E, and F). When the mutant was tested on A. afraspera, no significant effect of the mutation was observed on the plant growth, the number of nodules per plant, and the nitrogenase activity (Fig. 4A, C, and D). However, confocal microscopy observations of the nodules showed that the bacteroids' shape was disturbed. Instead of differentiating into long rod-shaped bacteroids as observed for the WT strain, the mutant cells exhibited a polar distortion giving them a sperm-like shape (Fig. 4G and $\mathrm{H}$ ).

In comparison with the ORS285 $\triangle D D$-CPasel mutant, the phenotype of the $B$. diazoefficiens $\triangle D D$-CPasel mutant on A. afraspera was much more drastic. Plants inoculated with the $B$. diazoefficiens $\triangle D D$-CPase1 mutant were smaller, contained a lower number of nodules (threefold less) and the nitrogenase activity was less than $10 \%$ of the activity measured on plants inoculated with the WT USDA110 strain (Fig. 5A, B, and D). On soybean, the mutant was altered in its symbiotic efficiency, but the phenotype was less severe and resulted from a reduced number of nodules (Fig. 5A, C, and D). Interestingly, cytological analysis of the nodules by confocal microscopy and TEM showed that the mutation had no effect on the bacteroid shape in the soybean nodules (U morphotype) (Fig. 5E, F, I, J, M and $\mathrm{N}$ ), whereas in A. afraspera nodules (E morphotype), the $D D$ CPase 1 mutation led to bacteroids with aberrant morphological shapes (Fig. 5G, H, K, L, O, and P). Taken together, these data indicate that the DD-CPasel mutation has an impact on the symbiotic interaction of all the tested Bradyrhizobium strains with their host plants but the symptoms and the severity of the phenotypes appear to be plant- and bacterium-dependent (Supplementary Table S2).

\section{DISCUSSION}

The morphological transition of rhizobia during their symbiotic interaction with some legumes is a surprising phenomenon. It has been known for several decades that it is the host plant that imposes a particular shape on its endosymbiotic population.

Fig. 2. Symbiotic properties of ORS278 $\triangle D D$-CPase mutants on Aeschynomene indica. A, Comparison of the growth of the plants (aerial part) not inoculated (NI) or inoculated with the ORS278 strain and the ORS278 $D D D$-CPase mutants (at 14 days postinoculation). B, Aspect of the nodules elicited by the ORS278 $\triangle D D$-CPase 1 mutant and $\mathbf{C}$, the wild-type (WT) strain. The white arrows indicate examples of necrotic nodules. D, Acetylene-reducing activity (ARA) in A. indica nodules induced by Bradyrhizobium sp. strain ORS78 and the ORS278 $\triangle D D$-CPase mutants. E, Number of nodules per plant elicited by Bradyrhizobium sp. strain ORS78 and the ORS278 $D D D$-CPase mutants. Error bars in D and E represent standard deviation ( $n=10)$. Double asterisks above the error bars indicate significant differences at $P<0.01$ (Tukey's honestly significant difference test). F, Flow cytometry analysis of the DNA content by propidium iodide fluorescence in free-living bacteria or bacteroids isolated from $A$. indica nodules. Light blue, free-living ORS278 WT strain; light orange, free-living ORS278 $D D D$-CPase 1 mutant; light purple, ORS278 WT bacteroids; light red, ORS278 $D D D$-CPase1 bacteroids. G to J, Transversal sections of nodules elicited by ORS278 (G) or the ORS278 $D D D$-CPase 1 mutant (H to J). Note the infection of the gusA-tagged mutant bacteria is blocked at the level of the nodule epidermis $(\mathrm{H})$, the brown color of the central tissue corresponding to plant defense reactions, and a WT-like nodule elicited by the mutant $(\mathrm{J})$, with some areas containing a visible brown pigment. Bars $=250 \mu \mathrm{M}$. K, Confocal microscopy analysis of nodules elicited by ORS278 and $\mathbf{L}$ and $\mathbf{M}$, the ORS278 $D D$-CPase 1 mutant ( $\mathrm{L}$ and $\mathrm{M}$ ). Note that the brown pigment as observed using light microscopy has a red autofluoresence. $\mathbf{N}$ to $\mathbf{R}$, Confocal microscopy images showing the morphology of the intracellular bacteria. The ORS278 bacteroids are spherical (O), whereas in aborted nodules the ORS278 $D D$-CPase 1 cells are rod shaped $(\mathrm{P})$ and a mixture of elongated, irregularly shaped and extremely enlarged spherical bacteroids are found in WT-like nodules (N, Q, and R). In R, the cytoplasm of some host cells is green, suggesting the burst of some bacteroids releasing their green fluorescent protein. Bars in $\mathrm{K}$ and $\mathrm{M}=250 \mu \mathrm{m}$ and in $\mathrm{L}$ and $\mathrm{N}$ to $\mathrm{R}=10 \mu \mathrm{m}$. 
However, it remains unclear whether this morphological change confers a functional advantage for one of the two partners and how the plant governs this morphogenesis process, although the involvement of the host plant cell produced NCR peptides and the bacterial BacA or BclA peptide transporters have been firmly established (Czernic et al. 2015; Guefrachi et al. 2015; Haag et al. 2013; Van de Velde et al. 2010). Here, we identified, in Bradyrhizobium symbionts of Aeschynomene legume species, a PGN remodeling enzyme, DD-CPase1, as a new actor in the morphological bacteroid differentiation process. This enzyme plays a specific symbiotic role, more or less drastic, depending on the host plant, while it is dispensable for free-living growth or for the formation of U-morphotype bacteroids.

For all three Bradyrhizobium strains tested, the DD-CPase1 mutants were affected in at least two different stages of the symbiotic process. First, DD-CPase 1 mutants of strains ORS278 and ORS285 induced a large number of necrotic nodules on A. indica roots. Bacterial surface components play an important role in recognition by the plant and in evasion of the plant immune system (Mithöfer 2002). Interestingly, it has been described in E. coli that perturbations in the PGN structure due to $D D$-CPase mutation can alter the microarchitecture of the bacterial outer membrane structures, such as flagella, adhesins, or secretory complex polysaccharides, that participate in biofilm formation (Gallant et al. 2005; Ghosh et al. 2008). It is assumed that the macromolecules of the outer membrane must pass through the PGN layer to be properly displayed on the bacterial surface and, for this, a localized remodeling of the PGN is required to permit this transit, a process that could be compromised in $D D$ CPase mutants (Gallant et al. 2005). Similarly, the DD-CPases 1 mutation in Bradyrhizobium strains could alter the assembly or the function of large molecular complexes on the bacterial surface, such as LPS, EPS, or capsular polysaccharide (KPS), which are important for inhibition of plant defenses or act as signals for the establishment of symbiosis. However, the colony morphology of the DD-CPases 1 mutants does not suggest a large alteration in the production of these envelope structures. On the other hand, it is possible that the DD-CPases 1 mutants release a higher amount of PGN fragments (muropeptides) or modified muropeptides that directly activate the plant immune system, thereby blocking further infection. Indeed, it is known that growing bacterial cells release muropeptides in the culture medium, which have been shown in pathogenic bacteria to elicit plant defense reactions (Goodell and Schwarz 1988; Gust et al. 2007). Further experiments will be required to discriminate whether the defects in the early steps of the symbiotic process observed in the DD-CPasel mutants result from direct or indirect consequences, or both, of PGN modifications.

The second symbiotic stage that is drastically affected by the DD-CPasel mutation is the bacteroid differentiation step.
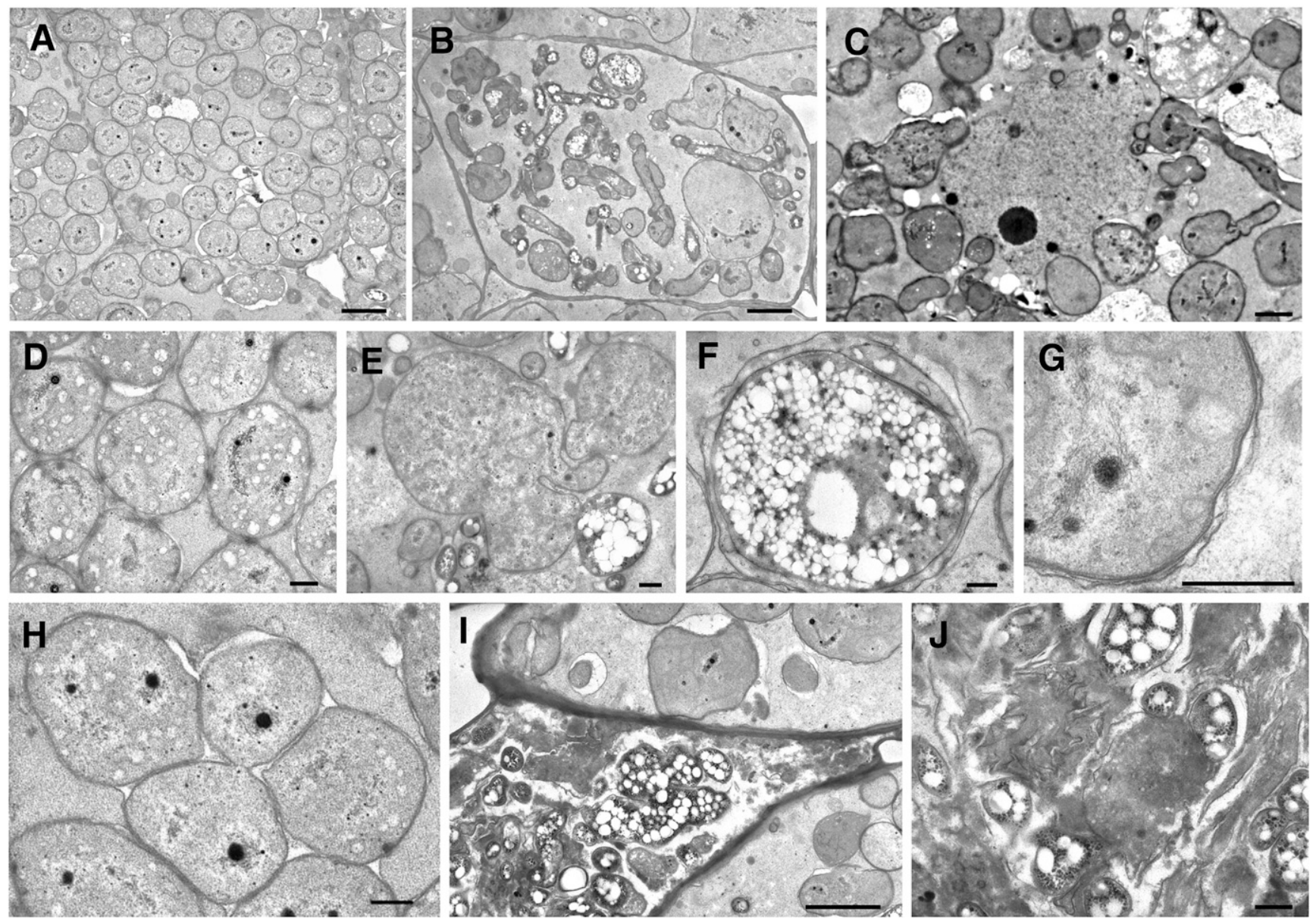

Fig. 3. Ultrastructure of bacteroids of ORS278 wild-type (WT) strain and the ORS278 $D D D$-CPase1 mutant in Aeschynomene indica nodules. A to J, TEM micrographs of nodules elicited by the ORS278 strain (A, D, H) and of nodules elicited by the ORS278 $\triangle D D$-CPase1 mutant (B, C, E, F, G, I, J). Note in A and $\mathrm{D}$, corresponding to a WT nodule, that the host cells are filled with spherical bacteroids, whereas in nodules elicited by the ORS278 $D D D$-CPase1 mutant, the bacteroids display different morphological irregularities (B, C, and E). In $\mathrm{H}$, note that the WT bacteroids can divide despite their spherical shape. F is a higher magnification of $\mathrm{B}$, showing that some mutant bacteroids accumulate polyhydroxybutyrate (white granules). Details of the cell-wall ultrastructure of mutant bacteroids can be seen in G. Micrographs I and $\mathrm{J}$ show host cells invaded by mutant bacteroids that are collapsed; $\mathrm{J}$ is a higher magnification of I, showing ghost bacteria. Scale bars in A, B, C, and I $=2 \mu \mathrm{m}$ and D, E, F, G, J and $\mathrm{H}=0.5 \mu \mathrm{m}$. 
Interestingly, this alteration was observed on both $A$. afraspera and $A$. indica species that lead to different bacteroid morphotypes (E and S morphotype, respectively) and in the three tested Bradyrhizobium strains but no alteration on the bacteroid shape could be observed in the case of $B$. diazoefficiens USDA110 in soybean nodules. In this last case, the host plant does not impose a morphological transition of their endosymbiotic bacteria (U-morphotype bacteroids). This suggests that the DD-CPase1 could constitute one of the bacterial targets on which the host plant acts to impose a particular bacteroid morphotype. It has been shown recently that Aeschynomene species use NCR peptides to control the bacteroid differentiation process (Czernic et al. 2015), a modus operandi that is very similar to the one described in Medicago species (Van de Velde et al. 2010). NCR are related to antimicrobial peptides of innate immunity that convert the bacteria in a differentiated, enlarged, and polyploid state (Van de Velde et al. 2010). Recent studies revealed that the Medicago truncatula NCR247 peptide interacts with many bacterial proteins and, in particular, with FtsZ, a conserved bacterial cell-cycle protein required for septum formation and cell division (Farkas et al. 2014; Penterman et al. 2014). It is supposed that this interaction inhibits bacterial cell division, which leads to an increase of the bacteroid ploidy level. The DD-CPase1 differs from other DD-CPases by the presence of an additional SPOR domain, which has been shown, in E. coli, to permit a septal localization of the proteins (Arends et al. 2010). This leads us to hypothesize that DD-CPasel proteins constitute, as FtsZ, septal ring proteins that play a significant role in daughter cell separation, probably by relaxing the PGN structure at the fission site or by contributing to the correct positioning of the FtsZ ring itself, a putative role that has been proposed for the DD-CPase PBP5 in E. coli (Potluri et al. 2012). The occasional divisions of WT bacteroids and the dramatic increase in size and ploidy level of DD-CPasel mutant bacteroids observed in A. indica support this assumption. Bacteria of the order Rhizobiales, to which the bradyrhizobia and other rhizobia belong, have a unique unipolar growth mechanism, implying lipid, membrane protein and PGN synthesis at one pole of the cell only (Brown et al. 2012; Cameron et al. 2014, 2015). This particular growth mechanism requires a dynamic relocalization of the FtsZ protein at the growing pole during cell elongation and at the mid-cell during division (Cameron et al. 2014). Potentially the DD-CPase1 protein is also involved in this polar growth mechanism and could explain the formation by the DD-CPasel mutants of bacteroids with branches, bulges, or polar distortions.

The absence of a phenotype observed for the DD-CPasel mutants cultivated in free-living conditions or in the soybean nodule context could result from functional redundancy of homologous proteins or other PGN remodeling enzymes that could compensate in this condition for the lack of the DDCPase1. On the other hand, during symbiosis with Aeschynomene spp., NCR peptides could transcriptionally or post-transcriptionally differently regulate the activity of these PGN remodeling enzymes, resulting in a prominent role of DD-CPase 1 that could no longer be compensated. It is also necessary to highlight that, in

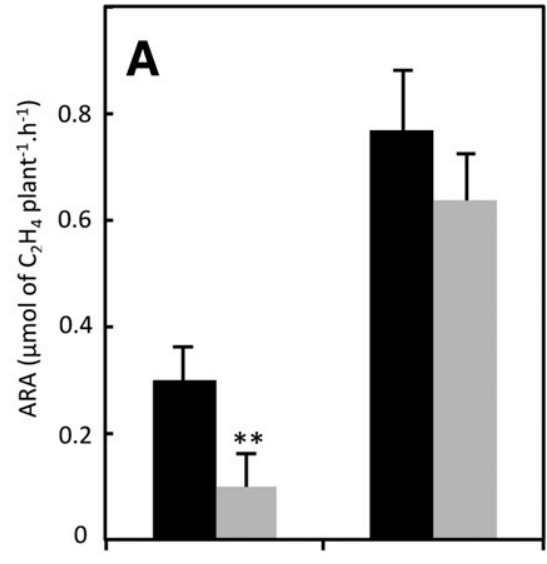

A. indica
A. afraspera
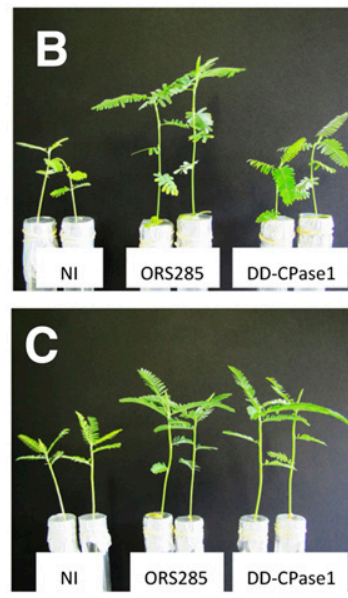

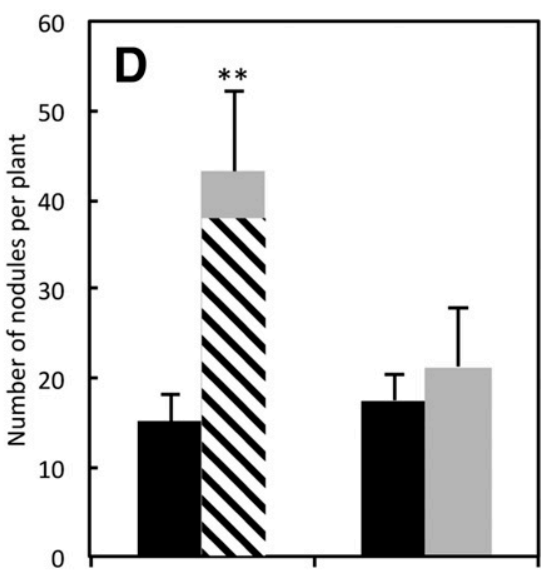

A. indica
A. afraspera
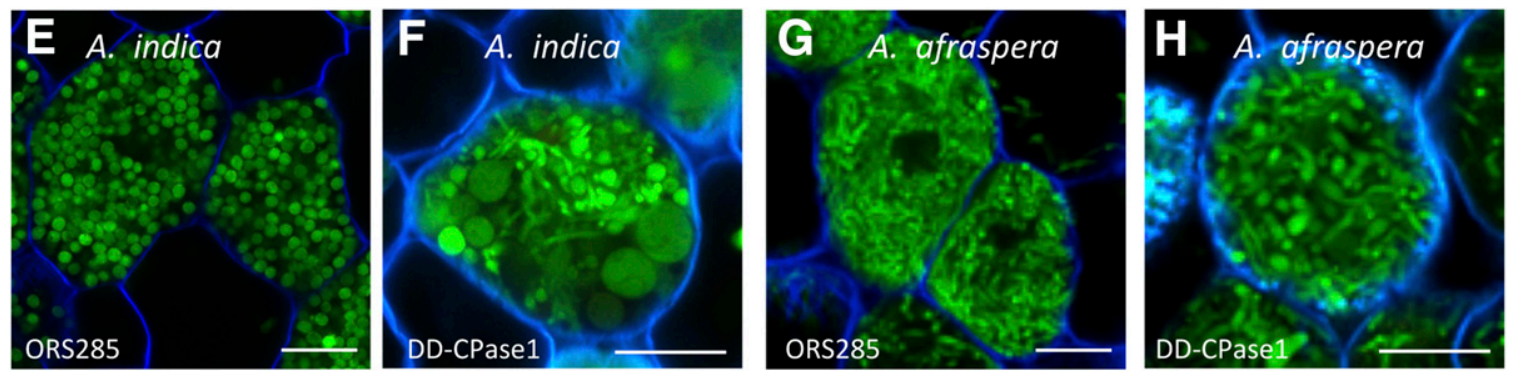

Fig. 4. Symbiotic properties of the ORS285 $\triangle D D$-CPase1 mutant on Aeschynomene indica and A. afraspera. A, Acetylene-reducing activity (ARA) in A. indica and A. afraspera inoculated with Bradyrhizobium ORS285 (black bars) and the ORS285 $\triangle D D$-CPase1 mutant (gray bars). Error bars represent standard deviation (SD) $(n=10)$. Double asterisks above the error bars indicate significant differences at $P<0.01$ (Tukey's honestly significant difference [HSD] test). B, Comparison of the growth of A. indica and C, A. afraspera not inoculated (NI) or inoculated with Bradyrhizobium ORS85 and the ORS285 $\triangle D D$-CPase 1 mutant (at 14 days postinoculation). D, Number of nodules per plant of A. indica and A. afraspera plants inoculated with Bradyrhizobium ORS285 (black bars) and the ORS285 $\triangle D D$-CPase1 mutant (gray bars). The number of yellow, necrotic nodules are indicated by a hatched bar. Error bars represent SD $(n=10)$. Double asterisks above the error bars indicate significant differences at $P<0.01$ (Tukey's HSD test). E to H, Confocal microscopy images showing the morphology of the intracellular bacteria. Nodules of A. indica elicited by ORS285 (E) and the ORS285 $\triangle D D$-CPase1 mutant (F). Nodules of A. afraspera elicited by ORS285 (G) and the ORS285 $\triangle D D$-CPase1 mutant $(\mathrm{H})$. Scale bars $=10 \mu \mathrm{m}$. 
Aeschynomene plants, the severity of the $D D$-CPasel mutation differs according to the strain. For example, in A. afraspera, the ORS285 $\triangle D D$-CPase1 bacteroids, although being malformed, still maintained a high nitrogenase activity, contrarily to the
B. diazoefficiens USDA110 mutant. Besides, the functional redundancy between the DD-CPases that could be more pronounced in one strain compared with the other, it is also possible that these differences are related to a variation in the ability of the mutants to
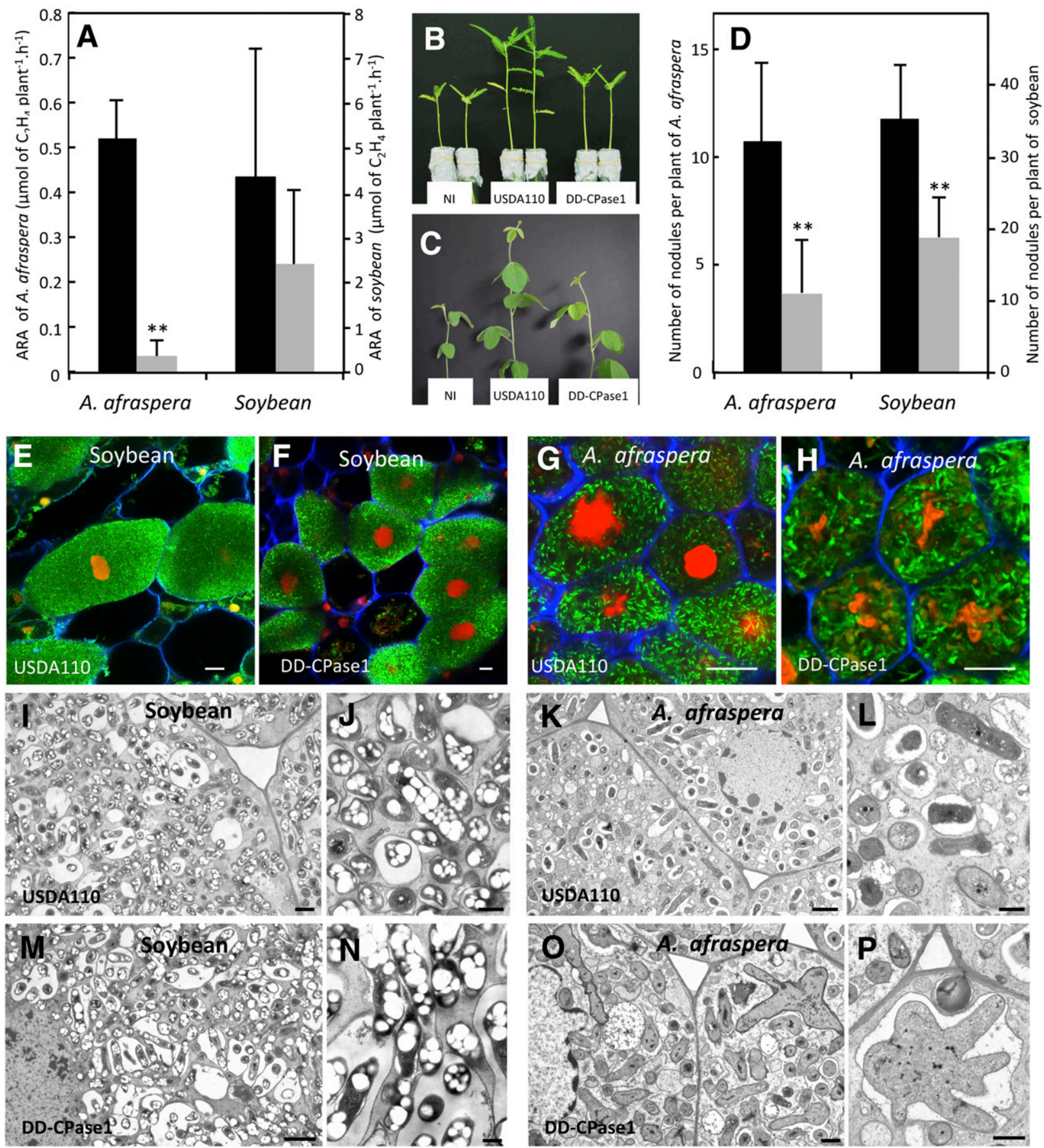

Fig. 5. Symbiotic properties of the USDA110 $D$ DD-CPase1 mutant on soybean and Aeschynomene afraspera. A, Acetylene-reducing activity (ARA) in soybean and A. afraspera nodules induced by Bradyrhizobium diazoefficiens USDA110 (dark bars) and the USDA110 $D D D$-CPase1 mutant (gray bars). Error bars represent standard deviation (SD) ( $n=7$ for soybean; $n=10$ for $A$. afraspera). Double asterisks above the error bars indicate significant differences at $P<0.01$ (Tukey's honestly significant difference [HSD] test). B, Comparison of the growth of A. afraspera and $\mathbf{C}$, soybean plants not inoculated (NI) or inoculated with B. diazoefficiens USDA110 strain and the USDA110 $\triangle D D$-CPase1 mutant (at 19 and 21 days postinoculation [dpi], respectively). D, Number of nodules per A. afraspera and soybean plant inoculated with B. diazoefficiens USDA110 (dark bars) and the USDA110 $\Delta D D$-CPase1 mutant (at 19 and 21 dpi, respectively). Error bars represent SD ( $n=7$ for soybean; $n=10$ for $A$. afraspera). Double asterisk above the error bars indicate significant differences at $P<0.01$ (Tukey's HSD test). $\mathbf{E}$ to $\mathbf{H}$, Confocal microscopy images showing the morphology of the intracellular bacteria. Nodules of soybean elicited by $B$. diazoefficiens USDA110 (E) and the USDA110 $\triangle D D$-CPase1 mutant (F). Nodules of A. afraspera elicited by B. diazoefficiens USDA110 (G) and the USDA110 $\triangle D D$-CPase 1 mutant $(\mathrm{H})$. Scale bars are $10 \mu \mathrm{m}$. I to $\mathbf{P}$, Transmission electron micrographs of nodules elicited by $B$. diazoefficiens USDA110 strain and the USDA110 $\Delta D D$ CPase1 mutant. Shown are soybean nodules elicited by B. diazoefficiens USDA110 (I, J) and the USDA110 $\triangle D D$-CPase1 mutant (M, N) and A. afraspera nodules elicited by $B$. diazoefficiens USDA1 $10(\mathrm{~K}, \mathrm{~L})$ and the USDA110 $\Delta D D$-CPase 1 mutant $(\mathrm{O}, \mathrm{P})$. Scale bars in $\mathrm{K}$ and $\mathrm{M}=2 \mu \mathrm{m}$; in $\mathrm{I}, \mathrm{O}$, and $\mathrm{P}=1 \mu \mathrm{m}$; and in $\mathrm{J}, \mathrm{L}$, and $\mathrm{N}=0.5 \mu \mathrm{m}$. 
cope with various plant stresses (e.g., oxidative, osmotic, or acid stresses).

In conclusion, our study demonstrates that modifications of PGN structure in Bradyrhizobium DD-CPase 1 mutants trigger plant defense reactions limiting infection and nodule development. It remains to identify the signals activating the plant immune system in these mutants. Moreover, we demonstrate that the remodeling PGN enzyme, DD-CPase1, is required for normal bacteroid differentiation in host plants that produce NCR peptides and impose a morphological differentiation and endoreduplication of the bacteroids. It will be particularly exciting to explore the possibility of a direct interaction of DDCPase1 with NCR peptides leading to the endoreduplication of the bacteroids.

The bacterial surface is a multilayered and complex structure, composed of many different macromolecules such as lipids, including LPS and hopanoids, EPS, KPS, periplasmic glycans, and peptidoglycans. Since the establishment of the rhizobium-legume symbiosis involves a continuous direct cell-to-cell contact between the microsymbiont and the host environment, it is not surprising that many molecular studies performed over the last several decades have highlighted a key role for most of these envelope components of rhizobium bacteria in symbiosis (Brown et al. 2011; Gibson et al. 2008; Haag et al. 2013; Silipo et al. 2014). However, to our knowledge no studies demonstrated the involvement of PGN and our work is filling now this gap.

\section{MATERIALS AND METHODS}

\section{Bacterial strains and growth conditions.}

Bradyrhizobium sp. strains ORS278 and ORS285 and derivatives were grown in yeast manitol (YM) medium at $34^{\circ} \mathrm{C}$ (Vincent 1970). The B. diazoefficiens USDA110 strain and the $D D$-CPase 1 mutant derivative were grown in the same medium but at $28^{\circ} \mathrm{C}$. When required, the media were supplemented with the appropriate antibiotics. Antibiotics were used at the following concentrations (micrograms per milliliter): kanamycin, 50 or 100; chloramphenicol, 20; tetracycline, 50, nalidixic acid, 25, and cefotaxime, 20.

\section{Construction of bacterial mutants.}

Standard molecular biology techniques were used for all cloning work. All primers used for cloning of DNA fragments are listed in Supplementary Table S3. For the construction of Bradyrhizobium sp. strain ORS278 mutants in the genes DDCPase 1 (BRADO4549), DD-CPase2 (BRADO3826), DD-CPase3 (BRADO6583), and the Bradyrhizobium sp. strain ORS85 mutant in the gene DD-CPase1 (Brao285v1_1580075), 400- to 500-bp internal fragments were amplified by polymerase chain reaction (PCR) and were cloned into the plasmid pVO155-npt2-GFP. This plasmid, which is nonreplicative in Bradyrhizobium strains, is a derivative of the plasmid pVO155 (Oke and Long 1999), which carries the promoterless gusA gene and a constitutively expressed gfp gene (Okazaki et al. 2016). The pVO155 plasmid has been used successfully for observing mutant phenotypes on plants in a diversity of bacteria, including other rhizobia (Sinorhizobium and Cupriavidius spp.), plant growth-promoting Burkholderia spp., pathogenic Xanthomonas spp., and others (Boulanger et al. 2014; Onofre-Lemus et al. 2009; Remigi et al. 2014; Tian et al. 2012). Its stability was verified and confirmed in the plant environment for at least Xanthomonas species (Boulanger et al. 2014; Darsonval et al. 2008). The resulting plasmids were then transferred into E. coli S17-1 strain to introduce the construction in ORS278 or ORS285 strains by mating, as previously described (Giraud et al. 2010). The pVO155-npt2-GFP insertions in all constructed mutants were stably maintained within the nodules in the absence of antibiotic selection, because histological analysis by confocal microscopy of nodules showed that, in all cases, the complete bacterial population was GFP-positive, demonstrating the maintenance of the plasmid. For the construction of the B. diazoefficiens USDA110 mutant in the gene DD-CPase1 (blr5156), the same insertional inactivation strategy was applied, except that we used the nonreplicative plasmid pSUP202pol4 that carries a tetracycline-resistance gene (Fischer et al. 1993)

A deletion mutant of the DD-Cpase1 gene in strain ORS278 was obtained as follows. The 750-bp upstream and downstream regions of the DD-Cpasel gene were obtained by PCR. The two regions were merged by sewing PCR and were cloned, first in the pGEM-T-easy vector (Promega Corp.) and, subsequently, in pNPTS129 after BamHI/KpnI liberation. This plasmid cannot replicate in Bradyrhizobium spp., it carries the $s a c B$ gene that induces bacterial death in the presence of sucrose and the kanamycin-resistance gene (Tsai and Alley 2000). Single recombinant clones were obtained by antibiotic selection and were verified by PCR. Double recombinant clones were then obtained by growth on sucrose without kanamycin addition. Candidate clones were verified for the loss of kanamycin resistance from the pNPTS129 plasmid, and the deletion of the DD-CPasel gene was verified by PCR.

\section{Stress assays.}

A 4-day-old bacterial culture of ORS278 and the different DD-CPase mutant derivatives in YM was washed and adjusted to reach an optical density at $600 \mathrm{~nm}\left(\mathrm{OD}_{600}\right)$ of 1 . Bacterial suspensions $(2 \mathrm{ml})$ were then mixed with $100 \mathrm{ml}$ of $42^{\circ} \mathrm{C}$ prewarmed YM soft agar $(0.8 \%$ agar $)$, and $5-\mathrm{ml}$ portions of this mixture were poured on YM plates. Filter disks were placed at the center of the plates, and aliquots $(5 \mu \mathrm{l})$ of SDS $(10 \% \mathrm{wt} / \mathrm{vol})$ were deposited on the disks. The diameters of growth inhibition areas were measured after incubation for 5 days at $37^{\circ} \mathrm{C}$.

For the $\mathrm{NaCl}$ resistance assay, the same bacterial suspensions were used to inoculate YM liquid medium containing various concentrations of $\mathrm{NaCl}$. Bacterial growth was monitored by following the increase in absorbance at $600 \mathrm{~nm}$ over time.

\section{PGN extraction and analysis.}

PGN extraction from bacterial cells was performed according to conventional protocols (Garcia-Bustos and Dougherty 1987; Girardin et al. 2003). Briefly, freeze-dried cells were suspended in ice-cold water and were added drop-wise to boiling 8\% SDS and were then boiled for $30 \mathrm{~min}$. After cooling to room temperature, the SDS-insoluble material was collected by centrifugation. The pellets were washed several times with water until no SDS could be detected. Enzymatic treatments with $\alpha$-amylase and trypsin were performed in order to remove high-molecular weight glycogen and covalently bound lipoprotein, respectively. Additional sequential washes with $8 \mathrm{M} \mathrm{LiCl}, 0.1 \mathrm{M}$ EDTA, and acetone were carried out.

The isolated peptidoglycans were digested overnight with the muramidase mutanolysin from Streptomyces globisporus ATCC21553 (Sigma-Aldrich) in phosphate buffer (12.5 mM at $\mathrm{pH} 5.3$ ) at $37^{\circ} \mathrm{C}$ and under constant shaking. The samples were boiled for $10 \mathrm{~min}$ to stop the hydrolysis, and insoluble contaminants were removed by centrifugation. The generated PGN fragments were dissolved in $0.5 \mathrm{M}$ sodium borate buffer $(\mathrm{pH}$ 9.0) and were incubated with sodium borohydride for $2 \mathrm{~h}$ at room temperature. The excess borohydride was destroyed with $2 \mathrm{M} \mathrm{HCl}$. The samples were desalted by using size-exclusion chromatography and were adjusted to $\mathrm{pH} 3$ to 4 with triflouroacetic acid. Finally, the muropeptides were fractionated by reverse-phase HPLC with an Agilent 1200 series HPLC system on a 250- by 4.6-mm, 3- $\mu$ m C18 Hypersyl ODS column. 
The samples were eluted with a gradient from $50 \mathrm{mM}$ to $75 \mathrm{mM}$ sodium phosphate, $15 \%$ methanol in $110 \mathrm{~min}$. Elution was monitored by measuring the absorbance at $206 \mathrm{~nm}$. For the identification of muropeptides, each peak of the HPLC profile was collected, vacuum dried, desalted, and subjected to matrixassisted laser desorption-ionization time of flight to determine the molecular mass of the components.

\section{Plant cultivation, symbiotic analysis, and microscopy.}

Two Aeschynomene species were used in this study, A. indica (LSTM accession number 19) and A. afraspera (LSTM accession number 1). The seeds were surface-sterilized by immersion in sulphuric acid under shaking for $45 \mathrm{~min}$. Seeds were abundantly washed with sterile distilled water and were incubated overnight in sterile water. Seeds were then transferred for 1 day at $37^{\circ} \mathrm{C}$ in the darkness on $0.8 \%$ agar plates for germination. Plantlets were transferred on the top of test tubes covered by aluminum paper for hydroponic culture in buffered nodulation medium (BNM) (Ehrhardt et al. 1992). Plants were grown in a $28^{\circ} \mathrm{C}$ growth chamber with a 16-h-light and 8-h-dark regime and $70 \%$ humidity. Seven days after transfer, each seedling was inoculated with $1 \mathrm{ml}$ of cell suspension resulting from a 5-day-old bacterial culture washed in BNM and adjusted to reach an $\mathrm{OD}_{600}$ of 1 .

The soybean (Glycine max Williams 82) seeds were cleaned with $100 \%$ ethanol for $30 \mathrm{~s}$ and were sterilized with bleach (1\%) for $5 \mathrm{~min}$. After several washes with sterile distilled water, seeds were germinated on tap water-agar plates at $28^{\circ} \mathrm{C}$ for 3 days. Seedlings were then transferred to Magenta boxes filled with BNM medium and were inoculated and grown as described above for Aeschynomene spp. plants. Plants were watered with BNM medium.

For nodulation and the nitrogen-fixation assay, 7 to 10 plants per condition were taken at 14 or $21 \mathrm{dpi}$ (in the case of $B$. diazoefficiens and the DD-CPasel mutant tested on soybean and $A$. afraspera) and were analyzed for the number of nodules and nitrogenase activity, as previously described (Bonaldi et al. 2010). The experiments were carried out in duplicate.

For cytological analysis of the nodules, semithin sections (30 to $40 \mu \mathrm{m}$ thick) were prepared using a vibratome (VT1000S; Leica, Nanterre). Nodules elicited by the GFPtagged strains were analyzed as previously described (Bonaldi et al. 2011). For the nodules elicited with the nontagged strains (B. diazoefficiens and its derivative DD-CPasel mutant) the nodule sections were incubated for $15 \mathrm{~min}$ in live/dead staining solution and were analyzed as previously described (Okazaki et al. 2016).

\section{Bacteroid purification and cytometry.}

Bacteroids were purified as described (Mergaert et al. 2006). Purified bacteroids and bacteria in free-living state (exponential phase) were fixed by heat treatment $\left(70^{\circ} \mathrm{C}, 10 \mathrm{~min}\right)$, were filtered through a $50 \mu \mathrm{M}$ nylon membrane, and were stained by $50 \mu \mathrm{g}$ of propidium iodide (PI) (Sigma Aldrich) per milliliter before flow cytometry analysis. The bacteroid preparations and similarly prepared suspensions of bacteria grown in culture were analyzed by flow cytometry using a MoFlo ASTRIOS flow cytometer (Beckman Coulter). The bacterial DNA content was assessed by the PI fluorescence with a 561-nm laser line. Each single event was recorded and analyzed with the FlowJo 10.0.6 software.

\section{ACKNOWLEDGMENTS}

This work was funded by the Agence Nationale de la Recherche, grant "BugsInACell" no. ANR-13-BSV7-0013. We thank A. De Felice from Università di Napoli Federico II for her technical assistance.

\section{LITERATURE CITED}

Arends, S. J., Williams, K., Scott, R. J., Rolong, S., Popham, D. L., and Weiss, D. S. 2010. Discovery and characterization of three new Escherichia coli septal ring proteins that contain a SPOR domain: DamX, DedD, and RlpA. J. Bacteriol. 192:242-255.

Bonaldi, K., Gourion, B., Fardoux, J., Hannibal, L., Cartieaux, F., Boursot, M., Vallenet, D., Chaintreuil, C., Prin, Y., Nouwen, N., and Giraud, E. 2010. Large-scale transposon mutagenesis of photosynthetic Bradyrhizobium sp. strain ORS278 reveals new genetic loci putatively important for nod-independent symbiosis with Aeschynomene indica. Mol. PlantMicrobe Interact 23:760-770.

Bonaldi, K., Gargani, D., Prin, Y., Fardoux, J., Gully, D., Nouwen, N., Goormachtig, S., and Giraud, E. 2011. Nodulation of Aeschynomene afraspera and A. indica by photosynthetic Bradyrhizobium sp. strain ORS285: The nod-dependent versus the nod-independent symbiotic interaction. Mol. Plant-Microbe Interact 24:1359-1371.

Boulanger, A., Zischek, C., Lautier, M., Jamet, S., Rival, P., Carrère, S., Arlat, M., and Lauber, E. 2014. The plant pathogen Xanthomonas campestris pv. campestris exploits $\mathrm{N}$-acetylglucosamine during Infection. MBio 5:e01527-14.

Bourcy, M., Brocard, L., Pislariu, C. I., Cosson, V., Mergaert, P., Tadege, M., Mysore, K. S., Udvardi, M. K., Gourion, B., and Ratet, P. 2013. Medicago truncatula DNF2 is a PI-PLC-XD-containing protein required for bacteroid persistence and prevention of nodule early senescence and defense-like reactions. New Phytol. 197:1250-1261.

Brown, D. B., Huang, Y. C., Kannenberg, E. L., Sherrier, D. J., and Carlson, R. W. 2011. An acpXL mutant of Rhizobium leguminosarum bv. phaseoli lacks 27-hydroxyoctacosanoic acid in its lipid A and is developmentally delayed during symbiotic infection of the determinate nodulating host plant Phaseolus vulgaris. J. Bacteriol. 193:4766-4778.

Brown, P. J., de Pedro, M. A., Kysela, D. T., Van der Henst, C., Kim, J., De Bolle, X., Fuqua, C., and Brun, Y. V. 2012. Polar growth in the Alphaproteobacterial order Rhizobiales. Proc. Natl. Acad. Sci. U.S.A. 109:1697-701.

Busset, N., De Felice, A., Chaintreuil, C., Gully, D., Fardoux, J., Romdhane, S., Molinaro, A., Silipo, A., and Giraud E. 2016. The LPS O-Antigen in photosynthetic Bradyrhizobium Strains is dispensable for the establishment of a successful symbiosis with Aeschynomene legumes. PLoS One. 11:e0148884

Cameron, T. A., Anderson-Furgeson, J., Zupan, J. R., Zik, J. J., and Zambryski, P. C. 2014. Peptidoglycan synthesis machinery in Agrobacterium tumefaciens during unipolar growth and cell division. MBio 5: e01219-14.

Cameron, T. A., Zupan, J. R., and Zambryski, P. C. 2015. The essential features and modes of bacterial polar growth. Trends Microbiol. 23:347-353.

Czernic, P., Gully, D., Cartieaux, F., Moulin, L., Guefrachi, I., Patrel, D., Pierre, O., Fardoux, J., Chaintreuil, C., Nguyen, P., Gressent, F., Da Silva, C., Poulain, J., Wincker, P., Rofidal, V., Hem, S., Arrighi, J. F., Mergaert, P., and Giraud, E. 2015. Convergent evolution of endosymbiont differentiation in Dalbergoid and IRLC legumes mediated by nodule-specific cysteine-rich peptides. Plant Physiol. 169:1254-1265.

Darsonval, A., Darrasse, A., Meyer, D., Demarty, M., Durand, K., Bureau, C., Manceau, C., and Jacques, M. A. 2008. The type III secretion system of Xanthomonas fuscans subsp. fuscans is involved in the phyllosphere colonization process and in transmission to seeds of susceptible beans. Appl. Environ. Microbiol. 74:2669-2678.

Ehrhardt, D. W., Atkinson, E. M., and Long, S. R. 1992. Depolarization of alfalfa root hair membrane potential by Rhizobium meliloti Nod factors. Science 256:998-1000.

Farkas, A., Maróti, G., Durgő, H., Györgypál, Z., Lima, R. M., Medzihradszky, K. F., Kereszt, A., Mergaert, P., and Kondorosi, É. 2014. Medicago truncatula symbiotic peptide NCR247 contributes to bacteroid differentiation through multiple mechanisms. Proc. Natl. Acad. Sci. U.S.A. 111: 5183-5188.

Fischer, H. M., Babst, M., Kaspar, T., Acuna, G., Arigoni, F., and Hennecke, H. 1993. One member of a groESL-like chaperonin multigene family in Bradyrhizobium japonicum is co-regulated with symbiotic nitrogen fixation genes. EMBO J. 12:2901-2912.

Gallant, C. V., Daniels, C., Leung, J. M., Ghosh, A. S., Young, K. D., Kotra, L. P., and Burrows, L. L. 2005. Common beta-lactamases inhibit bacterial biofilm formation. Mol. Microbiol. 58:1012-1024.

Garcia-Bustos, J. F., and Dougherty, T. J. 1987. Alterations in peptidoglycan of Neisseria gonorrhoeae induced by sub-MICs of $\beta$-lactam antibiotics. Antimicrob. Agents Chemother. 31:178-182.

Ghosh, A. S., Chowdhury, C., and Nelson, D. E. 2008. Physiological functions of D-alanine carboxypeptidases in Escherichia coli. Trends Microbiol. 16:309-317. 
Gibson, K. E., Kobayashi, H., and Walker, G. C. 2008. Molecular determinants of a symbiotic chronic infection. Annu. Rev. Genet. 42:413-441.

Girardin, S. E., Boneca, I. G., Carneiro, L. A. M., Antignac, A., Jehanno, M., Viala, J., Tedin, K., Taha, M. K., Labigne, A., Zahringer, U., Coyle, A. J., DiStefano, P. S., Bertin, J., Sansonetti, P. J., and Philpott, D. J. 2003. Nod1 detects a unique muropeptide from gram-negative bacterial peptidoglycan. Science 300:1584-1587.

Giraud, E., Moulin, L., Vallenet, D., Barbe, V., Cytryn, E., Avarre, J. C., Jaubert, M., Simon, D., Cartieaux, F., Prin, Y., Bena, G., Hannibal, L., Fardoux, J., Kojadinovic, M., Vuillet, L., Lajus, A., Cruveiller, S., Rouy, Z., Mangenot, S., Segurens, B., Dossat, C., Franck, W. L., Chang, W. S., Saunders, E., Bruce, D., Richardson, P., Normand, P., Dreyfus, B., Pignol, D., Stacey, G., Emerich, D., Verméglio, A., Médigue, C., and Sadowsky, M. 2007. Legumes symbioses: Absence of Nod genes in photosynthetic bradyrhizobia. Science 316: 1307-1312.

Giraud, E., Lavergne, J., and Vermeglio, A. 2010. Characterization of bacteriophytochromes from photosynthetic bacteria: Histidine kinase signaling triggered by light and redox sensing. Methods Enzymol. 471: 135-159.

Goodell, E. W., and Schwarz, U. 1988. Release of cell wall peptides into culture medium by exponentially growing Escherichia coli. J. Bacteriol. 162:391-397.

Guefrachi, I., Pierre, O., Timchenko, T., Alunni, B., Barriere, Q., Czernic, P., Villaécija-Aguilar, J. A., Verly, C., Bourge, M., Fardoux, J., Mars, M., Kondorosi, É., Giraud, E., and Mergaert, P. 2015. Bradyrhizobium BclA is a peptide transporter required for bacterial differentiation in symbiosis with Aeschynomene legumes. Mol. Plant-Microbe Interact 28:1155-1166.

Gust, A. A., Biswas, R., Lenz, H. D., Rauhut, T., Ranf, S., Kemmerling, B., Götz, F., Glawischnig, E., Lee, J., Felix, G., and Nürnberger, T. 2007. Bacteria-derived peptidoglycans constitute pathogen-associated molecular patterns triggering innate immunity in Arabidopsis. J. Biol. Chem. 282:32338-32348.

Haag, A. F., Arnold, M. F., Myka, K. K., Kerscher, B., Dall'Angelo, S., Zanda, M., Mergaert, P., and Ferguson, G. P. 2013. Molecular insights into bacteroid development during Rhizobium-legume symbiosis. FEMS (Fed. Eur. Microbiol. Soc.) Microbiol. Rev. 37:364-383.

Kondorosi, E., Mergaert, P., and Kereszt, A. 2013. A paradigm for endosymbiotic life: Cell differentiation of Rhizobium bacteria provoked by host plant factors. Annu. Rev. Microbiol. 67:611-628.

Ledermann, R., Bartsch, I., Remus-Emsermann, M., Vorholt, J. A., and Fischer, H. 2015. Stable fluorescent and enzymatic tagging of Bradyrhizobium diazoefficiens to analyze host-plant infection and colonization. Mol. Plant-Microbe Interact 28:959-967.

Mergaert, P., Uchiumi, T., Alunni, B., Evanno, G., Cheron, A., Catrice, O., Mausset, A. E., Barloy-Hubler, F., Galibert, F., Kondorosi, A., and Kondorosi, E. 2006. Eukaryotic control on bacterial cell cycle and differentiation in the Rhizobium-legume symbiosis. Proc. Natl. Acad. Sci. U.S.A. 103:5230-5235.

Mithöfer, A. 2002. Suppression of plant defence in rhizobia-legume symbiosis. Trends Plant Sci. 7:440-444.

Nelson, D. E., and Young, K. D. 2001. Contributions of PBP 5 and DDcarboxypeptidase penicillin binding proteins to maintenance of cell shape in Escherichia coli. J. Bacteriol. 183:3055-3064.

Okazaki, S., Kaneko, T., Sato, S., and Saeki, K. 2013. Hijacking of leguminous nodulation signaling by the rhizobial type III secretion system. Proc. Natl. Acad. Sci. U.S.A. 110:17131-17136.

Okazaki, S., Tittabutr, P., Teulet, A., Thouin, J., Fardoux, J., Chaintreuil, C., Gully, D., Arrighi, J. F., Furuta, N., Miwa, H., Yasuda, M., Nouwen, N.,
Teaumroong, N., and Giraud, E. 2016. Rhizobium-legume symbiosis in the absence of Nod factors: Two possible scenarios with or without the T3SS. ISME J. 10:64-74.

Oke, V., and Long, S. R. 1999. Bacterial genes induced within the nodule during the Rhizobium-legume symbiosis. Mol. Microbiol. 32:837-849.

Oldroyd, G. E. 2013. Speak, friend, and enter: Signalling systems that promote beneficial symbiotic associations in plants. Nat. Rev. Microbiol. 11: 252-263.

Onofre-Lemus, J., Hernández-Lucas, I., Girard, L., and CaballeroMellado, J. 2009. ACC (1-aminocyclopropane-1-carboxylate) deaminase activity, a widespread trait in Burkholderia species, and its growthpromoting effect on tomato plants. Appl. Environ. Microbiol. 75: 6581-6590.

Penterman, J., Abo, R. P., De Nisco, N. J., Arnold, M. F., Longhi, R., Zanda, M., and Walker, G. C. 2014. Host plant peptides elicit a transcriptional response to control the Sinorhizobium meliloti cell cycle during symbiosis. Proc. Natl. Acad. Sci. U.S.A. 111:3561-3566.

Potluri, L. P., de Pedro, M. A., and Young, K. D. 2012. Escherichia coli lowmolecular-weight penicillin-binding proteins help orient septal FtsZ, and their absence leads to asymmetric cell division and branching. Mol. Microbiol. 84:203-224.

Remigi, P., Capela, D., Clerissi, C., Tasse, L., Torchet, R., Bouchez, O., Batut, J., Cruveiller, S., Rocha, E. P. C., and Masson-Boivin, C. 2014. Transient hypermutagenesis accelerates the evolution of legume endosymbionts following horizontal gene transfer. PLoS Biol. 12 e1001942.

Santos, J. M., Lobo, M., Matos, A. P., De Pedro, M. A., and Arraiano, C. M. 2002. The gene bolA regulates dacA (PBP5), dacC (PBP6) and ampC (AmpC), promoting normal morphology in Escherichia coli. Mol. Microbiol. 45:1729-1740.

Silipo, A., Vitiello, G., Gully, D., Sturiale, L., Chaintreuil, C., Fardoux, J., Gargani, D., Lee, H. I., Kulkarni, G., Busset, N., Marchetti, R., Palmigiano, A., Moll, H., Engel, R., Lanzetta, R., Paduano, L., Parrilli, M., Chang, W. S., Holst, O., Newman, D. K., Garozzo, D., D’Errico, G., Giraud, E., and Molinaro, A. 2014. Covalently linked hopanoid-lipid A improves outer-membrane resistance of a Bradyrhizobium symbiont of legumes. Nat. Commun. 5:5106.

Tian, C. F., Garnerone, A. M., Mathieu-Demazière, C., Masson-Boivin, C., and Batut, J. 2012. Plant-activated bacterial receptor adenylate cyclases modulate epidermal infection in the Sinorhizobium meliloti-Medicago symbiosis. Proc. Natl. Acad. Sci. U.S.A. 109:6751-6756.

Tsai, J. W., and Alley, M. R. 2000. Proteolysis of the McpA chemoreceptor does not require the Caulobacter major chemotaxis operon. J. Bacteriol. 182:504-507.

Typas, A., Banzhaf, M., Gross, C. A., and Vollmer, W. 2012. From the regulation of peptidoglycan synthesis to bacterial growth and morphology. Nat. Rev. Microbiol. 10:123-136.

Van de Velde,W., Zehirov, G., Szatmari, A., Debreczeny, M., Ishihara, H., Kevei, Z., Farkas, A., Mikulass, K., Nagy, A., Tiricz, H., SatiatJeunaître, B., Alunni, B., Bourge, M., Kucho, K.-i., Abe, M., Kereszt, A., Maroti, G., Uchiumi, T., Kondorosi, E., and Mergaert, P. 2010. Plant peptides govern terminal differentiation of bacteria in symbiosis. Science 327:1122-1126.

Vasse, J., de Billy, F., and Truchet, G. 1993. Abortion of infection during the Rhizobium meliloti-alfalfa symbiotic interaction is accompanied by a hypersensitive reaction. Plant J. 4:555-566.

Vincent, J. 1970. A manual for the practical study of root-nodule bacteria. Blackwell Scientific Publications, Oxford, U.K.

Young, K. D. 2003. Bacterial shape. Mol. Microbiol. 49:571-580. 